\title{
Increased Risk of Thyroid Dysfunction Among Patients With Rheumatoid Arthritis
}

\author{
Qian $\mathrm{Li}^{1}$, Bin Wang ${ }^{1}$, Kaida $\mathrm{Mu}^{2}$, Jing Zhang ${ }^{2}$, Yanping Yang ${ }^{2}$, Wei Yao ${ }^{2}$, Jie Zhu ${ }^{2}$ and \\ Jin-an Zhang ${ }^{1 *}$ \\ ${ }^{1}$ Department of Endocrinology, Jinshan Hospital of Fudan University, Shanghai, China, ${ }^{2}$ Department of Endocrinology \& \\ Rheumatology, Affiliated Zhoupu Hospital, Shanghai University of Medicine and Health Sciences, Shanghai, China
}

\section{OPEN ACCESS}

Edited by:

Noriyuki Koibuchi,

Gunma University, Japan

Reviewed by:

Michele Colaci,

Università Degli Studi di Catania, Italy

Trevor Edmund Angell,

University of Southern California,

United States

*Correspondence:

Jin-an Zhang

zhangjinan@hotmail.com

Specialty section:

This article was submitted to

Thyroid Endocrinology,

a section of the journal

Frontiers in Endocrinology

Received: 14 October 2018 Accepted: 20 December 2018

Published: 11 January 2019

Citation:

Li Q, Wang B, Mu K, Zhang J, Yang Y, Yao W, Zhu J and Zhang J (2019)

Increased Risk of Thyroid Dysfunction Among Patients With Rheumatoid Arthritis. Front. Endocrinol. 9:799. doi: 10.3389/fendo.2018.00799
Background: Thyroid dysfunction seems to be common among rheumatoid arthritis (RA) patients, but the risk of thyroid dysfunction in RA has not been well-defined.

Methods: We performed a case-control study of 65 RA patients and 550 matched non-RA subjects to assess the risk of thyroid dysfunction among Chinese RA patients. A systematic review and meta-analysis was also conducted to comprehensively define the relationship between RA and thyroid dysfunction.

Results: The case-control study indicated that the prevalence of thyroid dysfunction was significantly higher in RA patients than controls ( $\mathrm{OR}=2.89, P<0.001)$. Further subgroup analyses revealed positive correlations of RA with hypothyroidism ( $\mathrm{OR}=2.28, P=0.006)$ and hyperthyroidism $(\mathrm{OR}=8.95, P<0.001)$. Multivariate logistic regression analysis revealed an independent association between RA and thyroid dysfunction (Adjusted $\mathrm{OR}=2.89,95 \% \mathrm{Cl} 1.63-5.12, P<0.001)$. Meta-analysis of 15 independent studies also showed an obviously increased risk of thyroid dysfunction among RA patients (RR $=2.86,95 \% \mathrm{Cl} 1.78-4.58, P<0.001)$. Further subgroup analysis showed RA could obviously increase risk of hyperthyroidism $(R R=2.73,95 \% \mathrm{Cl} 1.29-5.77, P=0.043)$ and hypothyroidism $(\mathrm{RR}=2.02,95 \% \mathrm{Cl} 1.49-2.74, P<0.001)$.

Conclusion: Our study provides strong evidence for the increased risk of thyroid dysfunction among RA patients. Screening of thyroid dysfunction may be recommended for RA patients.

Keywords: rheumatoid arthritis, thyroid dysfunction, meta-analysis, case-control study, hypothyroidism, hyperthyroidism, subclinical thyroid dysfunction, risk factors

\section{INTRODUCTION}

Rheumatoid arthritis (RA) is a chronic and systemic autoimmune disease which can result in constant inflammatory polyarthritis and continuous joint destruction, leading to damaged mobility and increased disability (1). The prevalence of RA in general population is $\sim 1 \%$, and RA is found to be related to some co-morbidities (2-4). The etiology of RA is still unclear and remain to be clarified, and both genetic and environment factors contribute to its etiology (5). Despite the clinical implications of RA itself, patients with RA are at increased risk of co-morbidities, for instance, cardiovascular disease (CVD) $(6,7)$. The mechanism underlying the increased risk of co-morbidities among RA patients is unclear, but researchers tend to attribute it to the inflammatory condition in RA patients $(8,9)$. 
Thyroid dysfunction mainly includes hyperthyroidism and hypothyroidism. Both hyperthyroidism and hypothyroidism can be categorized into overt and subclinical stages (10-12). Hyperthyroidism is defined by excess of thyroid hormones, and Graves' disease (GD) is its main etiology. Hypothyroidism is defined by insufficiency of thyroid hormones, and its most common etiology is Hashimoto's thyroiditis (HT). Both hyperthyroidism and hypothyroidism have obviously adverse impact on human health and can lead to higher risk of cardiovascular diseases and mortality. Previous studies observed that thyroid dysfunction was prevalent in RA patients, with the prevalence ranging from 6 to $34 \%(13,14)$. Thyroid function test is usually recommended for subjects with obvious clinical implications, like cold intolerance, loss of weight, elevated metabolism, or thyroid goiter $(10,15)$. Additionally, some guidelines suggest to conduct thyroid-related assessment in patients with type 1 diabetes or Addison's disease since those patients are at increased risk of thyroid dysfunction (16). However, conventional thyroid function test is not recommended in RA patients. Currently, the risk of thyroid dysfunction among RA patients has not been fully established. Herein we conducted a case-control study to evaluate both the prevalence and the risk of thyroid dysfunction among RA patients. A systematic review and meta-analysis was also conducted to comprehensively define the relationship between RA and thyroid dysfunction.

\section{METHODS}

\section{Participants}

A total of 65 consecutive RA patients near a 3-year period were recruited from the Outpatient and Inpatient departments of Jinshan Hospital, Shanghai, China. All patients were evaluated according to American Rheumatology Association classification criteria (17). The exclusion criteria included the following: individuals with a history of other rheumatic diseases [e.g., systemic sclerosis (SS), systemic lupus erythematosus (SLE)]; active infection; malignancy and intake of drugs known to cause thyroid dysfunction. Patients who underwent thyroid surgery in the past were also excluded from the study. Furthermore, a complete assessment with emphasis on symptoms and laboratory markers of thyroid dysfunction was conducted. Written informed consent was taken from all patients in accordance with the Declaration of Helsinki. A total of 550 ethnically and geographically matched subjects were recruited from a cross-sectional study in the general population of our area, which was conducted in 2016. All of those participants were from the Chinese Han population. Either 5 or 10 non-RA controls were matched to one RA patients by age and sex. The characteristics of the subjects in this study were presented in Table $\mathbf{1}$. The protocol was approved by the Ethics Committee of Jinshan Hospital of Fudan University.

\section{Data Collection}

All clinical and demographic data including sex, age, disease duration, treatment methods, C-reactive protein (CRP), rheumatoid factor (RF), anti-cyclic citrullinated peptide
TABLE 1 | Characteristic of subjects in the study.

\begin{tabular}{|c|c|c|c|}
\hline Variable & RA $(n=65)$ & Control $(n=550)$ & $P$ \\
\hline Sex (Female, \%) & 52 (80.0\%) & 425 (77.3\%) & 0.62 \\
\hline Age $(\text { mean } \pm S D)^{\star}$ & $59.58 \pm 11.64$ & $59.32 \pm 10.72$ & 0.86 \\
\hline Hypertension & $23(35.4 \%)$ & $268(48.7 \%)$ & 0.04 \\
\hline Type 2 diabetes & $4(6.2 \%)$ & $86(15.6 \%)$ & 0.05 \\
\hline RA duration & $7.12 \pm 8.58$ & - & - \\
\hline \multicolumn{4}{|c|}{ TREATMENT OF RA PATIENTS } \\
\hline Methotrexate & 17 (26.2\%) & - & - \\
\hline Glucocorticoid & 23 (35.4\%) & - & - \\
\hline Leflunomide & $10(15.4 \%)$ & - & - \\
\hline Tripterygium glycosides & $5(7.7 \%)$ & - & - \\
\hline NSAIDs & $9(13.8 \%)$ & - & - \\
\hline Traditional chinese medicine & $3(4.6 \%)$ & - & - \\
\hline
\end{tabular}

"Data was represented as mean $\pm S D$; RA, rheumatoid arthritis; NSAIDs, non-steroid anti-inflammatory drugs.

antibody (anti-CCP), and other variables were collected. Data of co-morbidities such as hypertension and type 2 diabetes mellitus (T2DM) were also collected. Furthermore, the level of free triiodothyronine (FT3), free thyroxine (FT4), circulating thyroid stimulating hormone (TSH), TSH receptor antibody (TRAb), antithyroglobulin antibody (TgAb), and antithyroid peroxidase antibody (TPOAb) as well as ultrasound examination and/or diffuse goiter were recorded. Thyroid dysfunction was determined by the combination of thyroid hormones and clinical symptoms, and was classified into hyperthyroidism (clinical or subclinical) and hypothyroidism (clinical or subclinical). Overt hyperthyroidism was characterized by a decreased TSH level together with elevated level of FT4, and subclinical hyperthyroidism was defined as decreased TSH level with normal FT4 level. Overt hypothyroidism was defined as an increased level of TSH and decreased FT4, while subclinical hypothyroidism ( $\mathrm{SCH}$ ) was defined as those with increased TSH level with normal FT4 level. The reference values for TSH, FT, and FT4 were $0.27-4.2 \mathrm{mIU} / \mathrm{L}, 3.1-6.8 \mathrm{pmol} / \mathrm{L}$, and $12.0-22.0$ $\mathrm{pmol} / \mathrm{L}$, respectively.

\section{Statistical Analysis}

All data were analyzed by Stata (version 12.0, StataCorp). The difference in sex, hypertension and T2DM between RA patients and controls were assessed using Chi-square test, and the difference in age was determined using $t$-test. The frequency of thyroid dysfunction between RA patients and controls was compared with Chi-square test, and odds ratio (OR) with $95 \%$ confidence interval $(95 \% \mathrm{CI})$ was calculated. Multiple logistic regression analysis was also conducted to evaluate the association between thyroid dysfunction and RA. Because both hypertension and T2DM were prevalent among RA patients and controls and there was some difference in their proportions, we thus conducted logistic regression analysis with adjustment for age, gender, hypertension and T2DM. Moreover, logistic regression analysis was also performed to assess the impact of disease duration on risk of thyroid dysfunction 
among RA patients. A $P<0.05$ was considered statistically significant.

\section{Systematic Review}

The systematic review and meta-analysis were done in accordance with the PRISMA guideline (18). Pubmed and Embase were searched with the following search strategy: (rheumatoid arthritis) AND (thyroid dysfunction OR hypothyroidism OR hyperthyroidism). There was no language restriction. The reference lists of included studies were also searched. We included observational studies, such as cohort studies, cross-sectional studies, and case-control studies, which compared the prevalence of thyroid dysfunction between RA patients and non-RA controls. Eligible studies must include RA patients and non-RA controls, while those enrolled patients with juvenile arthritis or psoriatic arthritis were excluded. The outcome of interest was the relative risk of thyroid dysfunction among RA patients compared with non-RA controls. Included studies need to provide risk estimates with $95 \% \mathrm{CI}$ for the association between $\mathrm{RA}$ and thyroid dysfunction, such as relative risk (RR) and OR, or provide other data which could be transformed into risk estimates. Case reports and studies containing overlapping data were excluded.

Data extraction was conducted using an extraction form, which mainly included study characteristics, participant characteristics, types of thyroid dysfunction and adjusted cofounders or matched factors. Quality assessment of included studies was conducted using Newcastle-Ottawa scale (NOS), and was based on participant selection, exposure evaluation, outcome evaluation and cofounders adjustment (19). Studies scoring 5 or fewer points were defined as studies with suboptimal quality, and those with 6 or more points had good quality. RR with $95 \% \mathrm{CI}$ was used to evaluate the risk of thyroid dysfunction among RA patients. Heterogeneity was assessed using the $\mathrm{I}^{2}$ statistic, and $\mathrm{I}^{2}>50 \%$ was deemed as high heterogeneity. Data were pooled using random-effects meta-analysis (20). Subgroup analysis was conducted based on type of hypothyroidism (Overt hypothyroidism; SCH). Publication bias was assessed by the funnel plot and Egger's test. Trim and fill method was utilized when publication bias existed. All analyses were conducted in Stata (version 12.0, StataCorp), and $P<0.05$ was considered statistically significant.

\section{RESULTS}

\section{Case-Control Study}

Among the RA patients enrolled in the study, $80.0 \%$ were female, and the mean age was 59.58 years. Both hypertension and T2DM were prevalent among RA patients and controls, and there was some difference in their proportions (Table 1). The profile of distinct subsets of thyroid dysfunction was displayed in Table 2. Among the RA patients, 21 (32.3\%) were diagnosed with thyroid dysfunction, 4 (6.2\%) of which were hyperthyroidism and the others were hypothyroidism (26.2\%). In contrast, only $14.2 \%$ individuals in the control group (78 cases) had thyroid dysfunction, including $4(0.7 \%)$ hyperthyroidism cases and 74 (13.5\%) hypothyroidism cases. Compared with the control group, the percentage of thyroid dysfunction was significantly increased in $\mathrm{RA}$ group $(\mathrm{OR}=2.89,95 \% \mathrm{CI} 1.63-5.12, P<0.001)$, which illustrated the increased risk of thyroid dysfunction in RA patients. Additionally, the proportions of hyperthyroidism and hypothyroidism in RA group were also increased compared with that in the control group $(\mathrm{OR}=8.95, P<0.001$; $\mathrm{OR}=2.28, P=$ 0.006). Furthermore, in comparison with controls, the number of subjects with overt hypothyroidism was significantly increased in RA group $(P<0.001)$ (Table 2$)$.

Outcomes from logistic regression analysis were shown in Table 3. In general, the results indicated that RA was independently associated with thyroid dysfunction $(\mathrm{OR}=3.03$, 95\%CI 1.68-5.48; $P<0.001)$. Further subgroup analysis showed

TABLE 3 | Outcomes in the relationship between RA and thyroid dysfunction from the logistic regression analysis.

\begin{tabular}{|c|c|c|c|}
\hline & $\boldsymbol{P}$ & OR $^{\star}$ & $95 \% \mathrm{Cl}$ \\
\hline Thyroid dysfunction & $<0.001$ & 3.03 & $1.68-5.48$ \\
\hline Hyperthyroidism & 0.001 & 11.30 & $2.54-50.29$ \\
\hline Overt Hyperthyroidism & 0.012 & 7.75 & $1.56-38.59$ \\
\hline Hypothyroidism & 0.007 & 2.35 & $1.26-4.40$ \\
\hline Overt Hypothyroidism & $<0.001$ & 17.95 & $4.88-66.01$ \\
\hline Subclinical thyroid dysfunction\# & 0.340 & 1.41 & $0.69-2.89$ \\
\hline Subclinical Hypothyroidism & 0.555 & 1.25 & $0.60-2.61$ \\
\hline
\end{tabular}

*Adjusted factors in the logistic regression analysis included age, gender and hypertension. "Subclinical thyroid dysfunction included subclinical hyperthyroidism and subclinical hypothyroidism.

TABLE 2 | The prevalence of thyroid dysfunction and its subgroup in RA patients and controls.

\begin{tabular}{|c|c|c|c|c|c|}
\hline & RA group $(n=65)$ & Control group $(n=550)$ & $\boldsymbol{P}$ & OR & $95 \% \mathrm{Cl}$ \\
\hline Thyroid dysfunction & $21(32.3 \%)$ & $78(14.2 \%)$ & $<0.001$ & 2.89 & $1.63-5.12$ \\
\hline Hyperthyroidism & $4(6.2 \%)$ & $4(0.7 \%)$ & $<0.001$ & 8.95 & $2.18-36.70$ \\
\hline Overt hyperthyroidism & $3(4.6 \%)$ & $4(0.7 \%)$ & 0.005 & 6.61 & $1.45-30.19$ \\
\hline Hypothyroidism & 17 (26.2\%) & 74 (13.5\%) & 0.006 & 2.28 & $1.24-4.17$ \\
\hline Overt hypothyroidism & $7(10.8 \%)$ & $4(0.7 \%)$ & $<0.001$ & 16.47 & $4.68-57.96$ \\
\hline Subclinical thyroid dysfunction & $11(16.9 \%)$ & $70(12.7 \%)$ & 0.344 & 1.40 & $0.70-2.80$ \\
\hline Subclinical hyperthyroidism & $1(1.5 \%)$ & $0(0 \%)$ & 0.05 & 25.60 & $1.03-635.1$ \\
\hline Subclinical hypothyroidism & $10(15.4 \%)$ & $70(12.7 \%)$ & 0.547 & 1.25 & 0.612 .56 \\
\hline
\end{tabular}

$R A$, rheumatoid arthritis. 


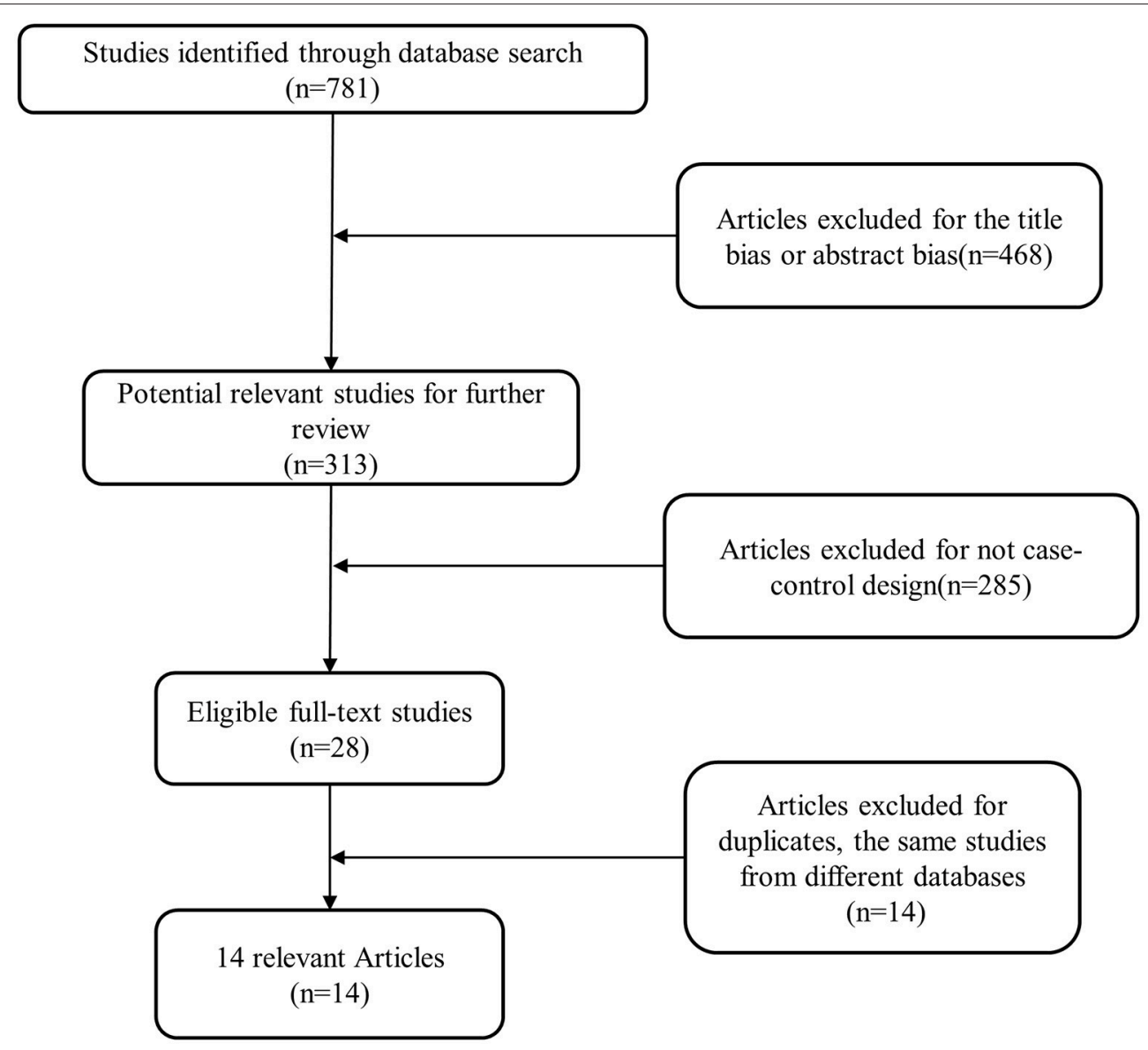

FIGURE 1 | The detailed procedures of study selection in the meta-analysis.

TABLE 4 | Characteristics of 15 studies included in the meta-analysis.

\begin{tabular}{|c|c|c|c|c|c|c|}
\hline \multirow[t]{2}{*}{ Author } & \multirow[t]{2}{*}{ Year } & \multirow[t]{2}{*}{ Region } & \multicolumn{2}{|c|}{ Participants } & \multirow[t]{2}{*}{ Types of thyroid dysfunction } & \multirow[t]{2}{*}{ Study design } \\
\hline & & & RA & Control & & \\
\hline Shiroky JB & 1993 & Canada & 119 & 108 & Dysfunction Hypothyroidism Hyperthyroidism & Case-control \\
\hline Andonopoulos AP & 1996 & Greece & 101 & 70 & Dysfunction Hypothyroidism Hyperthyroidism & Case-control \\
\hline Al-Awadhi AM & 1999 & Kuwait & 48 & 90 & Dysfunction Hypothyroidism SCH Overt hypothyroidism & Case-control \\
\hline Innocencio RM & 2004 & Brazil & 25 & 113 & Dysfunction Hypothyroidism SCH & Case-control \\
\hline Antonelli A & 2006 & Italy & 91 & 180 & Dysfunction Hypothyroidism SCH Hyperthyroidism & Case-control \\
\hline Al-Awadhi AM & 2008 & Kuwait & 177 & 577 & Dysfunction Hypothyroidism SCH Overt hypothyroidism Hyperthyroidism & Case-control \\
\hline Przygodzka M & 2009 & Poland & 100 & 55 & Dysfunction Hypothyroidism SCH Hyperthyroidism & Case-control \\
\hline Santos MJ & 2010 & Portugal & 98 & 102 & Hypothyroidism & Case-control \\
\hline McCoy SS & 2012 & USA & 650 & 650 & Hypothyroidism SCH & Cohort \\
\hline Kerola AM & 2014 & Finland & 7209 & None & Overt hypothyroidism & Case-control \\
\hline Wang SL & 2014 & Taiwan & 3657 & 14628 & Dysfunction Hypothyroidism Hyperthyroidism & Case-control \\
\hline Zamora-Legoff JA & 2016 & USA & 497 & 527 & Hypothyroidism & Case-control \\
\hline Tascilar K & 2016 & Canada & 1357 & 13570 & Hypothyroidism & Case-control \\
\hline Posselt RT & 2017 & Brazil & 210 & 141 & Hypothyroidism & Case-control \\
\hline Present Study & 2017 & China & 65 & 550 & Dysfunction Hypothyroidism Hyperthyroidism Overt hypothyroidism SCH & Case-control \\
\hline
\end{tabular}




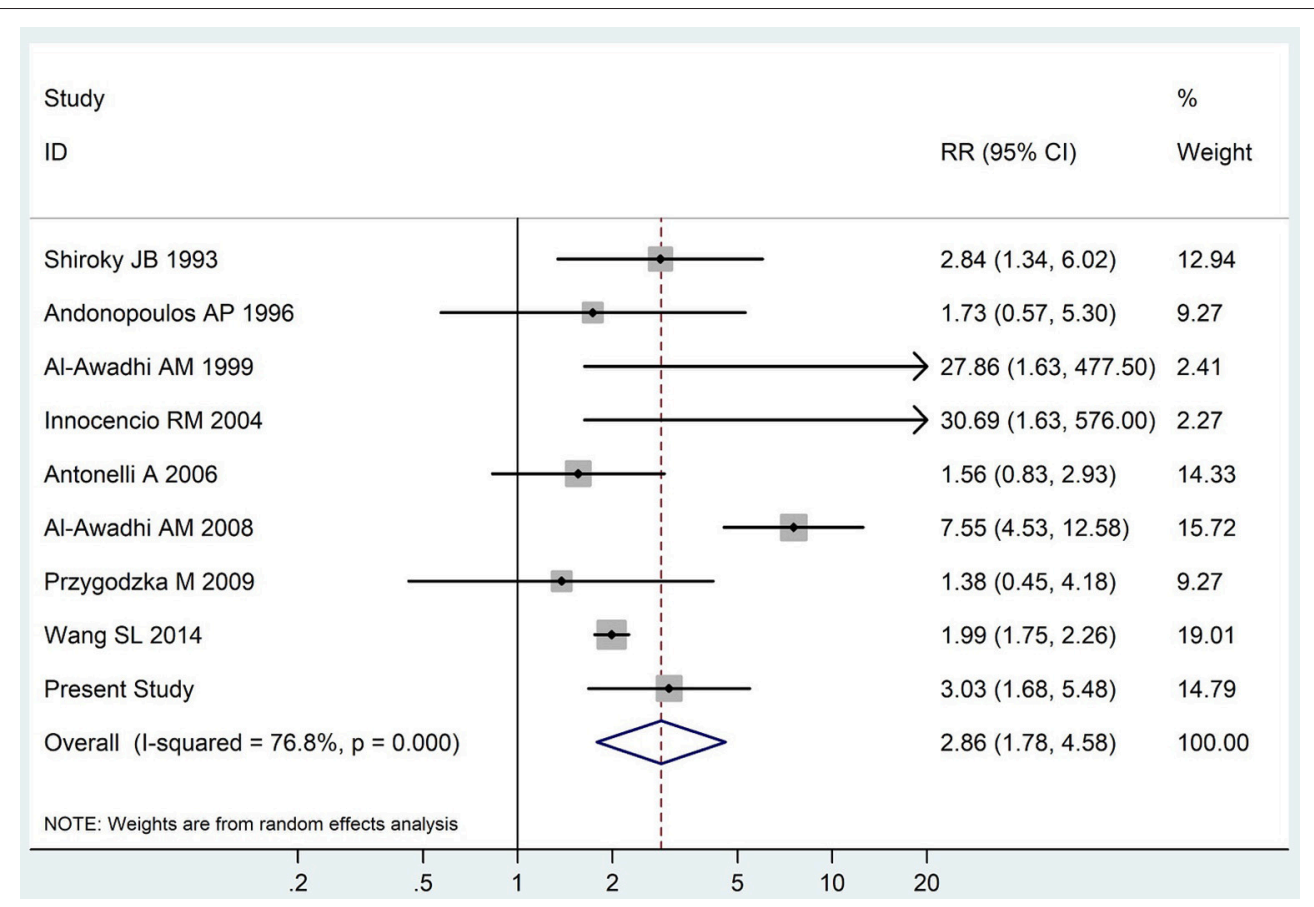

FIGURE 2 | Forest plot for the increased risk of thyroid dysfunction among RA patients (The diamond represents the pooled RR and 95\% CI).

that RA patients were at greater risk of hypothyroidism (OR $=2.35,95 \% \mathrm{CI} 1.26-4.40 ; P=0.007)$, especially for overt hypothyroidism $(\mathrm{OR}=17.95,95 \% \mathrm{CI} 4.88-66.01 ; P<0.001)$. Moreover, RA was also independently associated with increased risk of hyperthyroidism $(\mathrm{OR}=11.30,95 \% \mathrm{CI} 2.54-50.29, P=$ $0.001)$ and overt hyperthyroidism (OR $=7.75,95 \%$ CI 1.56-38.59; $P=0.012$ ). Logistic regression analysis in RA patients revealed that disease duration had no obvious impact on the risk of thyroid dysfunction (Adjusted OR $=0.95,95 \%$ CI 0.88-1.02; $P=0.17$ ).

\section{Meta-Analysis}

A total of 15 relevant reported studies together with our study were included in the meta-analysis. The detailed steps of selecting research was depicted in Figure 1. According to the selection criteria, 1,017 studies were excluded and 15 studies were included in the present study.

The summary of those 15 studies was displayed in Table 4. The meta-analysis demonstrated an significantly increased risk of thyroid dysfunction among RA patients $(\mathrm{RR}=2.86$, 95\% CI $1.78-$ 4.58; $P<0.001$; Figure 2). Further subgroup analysis revealed RA could obviously increase risk of hyperthyroidism $(\mathrm{OR}=2.73$, 95\%CI 1.29-5.77; $P=0.043$; Figure 3), hypothyroidism (OR $=2.02$, 95\%CI 1.49-2.74; $P<0.001$; Figure 4). Furthermore, the meta-analysis also indicated a strong correlation between overt hypothyroidism and RA, and the pooled RR was 5.31 (95\%CI 1.32-21.31; $P<0.001$; Figure 5). In addition, the analysis proved that RA patients were likely to have increased prevalence of subclinical thyroid dysfunction which including subclinical hyperthyroidism and clinical hypothyroidism, and the RR was 2.34 (95\%CI 1.25-4.37; $P=0.007$; Figure 6).

\section{DISCUSSION}

RA is a systemic and chronic disease which leads to symmetrical polyarthritis and progressive destruction of joint. The disease leads to disability and mortality if not treated. In our casecontrol study, we investigated 65 RA patients and 550 matched healthy individuals to evaluate the relationship between RA and thyroid dysfunction. Herein we found that patients with RA were likely to have increased prevalence of both hyperthyroidism and hypothyroidism, especially overt hypothyroidism. Subsequently, we performed a metaanalysis containing 15 distinct studies to further explore the relationship between RA and thyroid dysfunction, and found that RA was an important risk factor of thyroid dysfunction.

Thyroid dysfunction includes hypothyroidism and hyperthyroidism and is mainly induced by autoimmune thyroid disease (AITD) such as GD or HT $(21,22)$. Intriguingly, thyroid dysfunction is frequently accompanied by non-thyroid autoimmune diseases (22). The relationship between RA and thyroid dysfunction has been studied extensively in decades, but there is still lack of a definite conclusion (23). Numerous studies had looked into the correlation between RA and thyroid dysfunction and the earliest research can be traced back to 1,963 (24). By investigating $101 \mathrm{RA}$ and 70 controls, Andonopoulos et al. (25) found that the level of thyroid autoantibodies in RA patients was different from the controls. However, it failed to find significant difference between thyroid dysfunction and RA. Recently, a study in 2014 evaluated the association between rheumatic diseases and thyroid disorders, which suggested that 


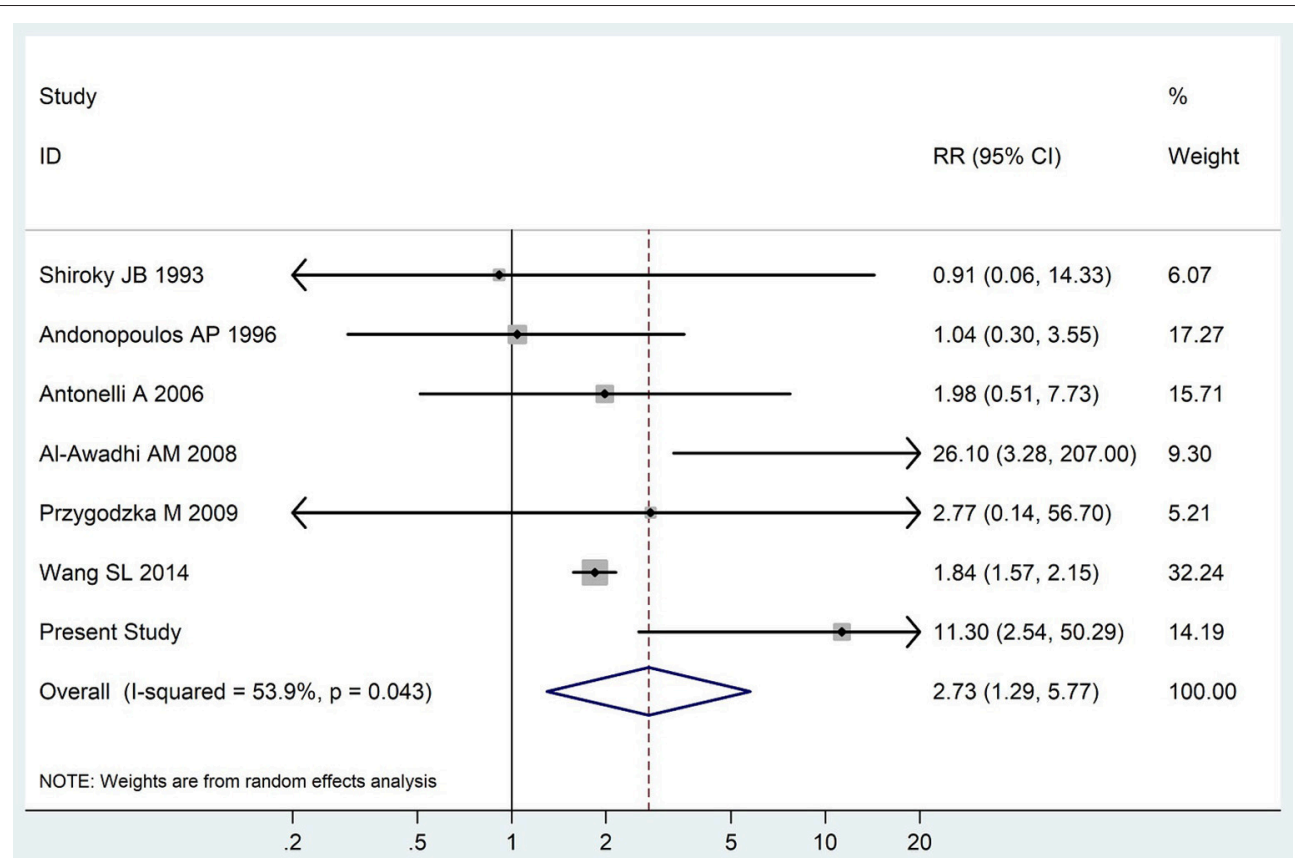

FIGURE 3 | Forest plot for the increased risk of hyperthyroidism among RA patients (The diamond represents the pooled RR and 95\% CI).

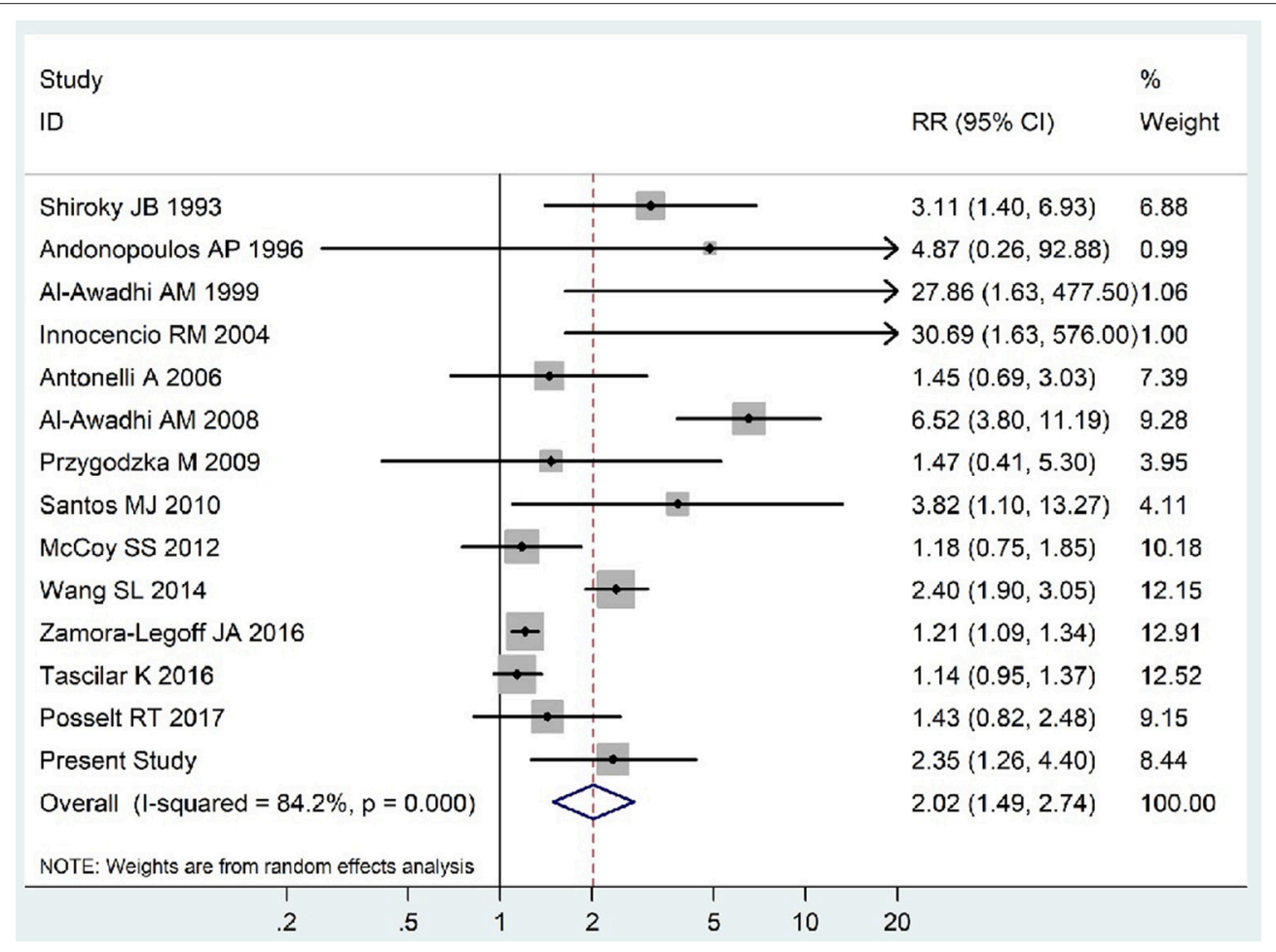

FIGURE 4 | Forest plot for the increased risk of hypothyroidism among RA patients (The diamond represents the pooled RR and 95\% CI).

thyroid-related antibodies were significantly increased in RA patients as well the occurrence of thyroid dysfunction (26). In our case-control study, we found that the prevalence of thyroid dysfunction in RA patients differed significantly from the controls, and RA patients had an increased prevalence of hypothyroidism. This result was in line with a recent study 

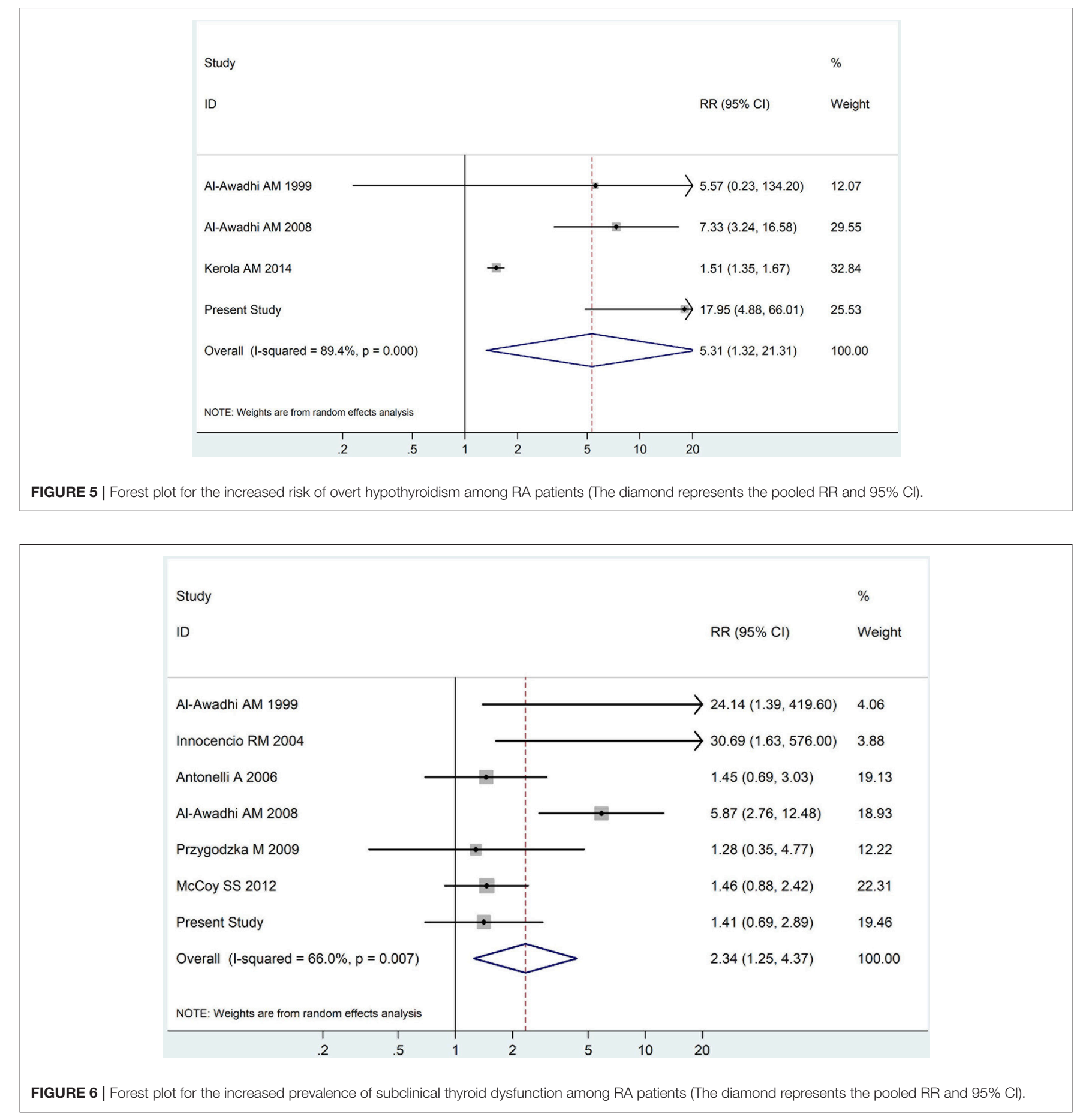

published in 2017, which demonstrated an obvious correlation between hypothyroidism and RA (27). In previous studies, more outcomes revealed the correlation between RA and hypothyroidism, but not hyperthyroidism. Our case-control study found that the incidence of hyperthyroidism in RA patients was significantly different from the controls, which provided evidence that RA patients may have the disposition toward hyperthyroidism. Except for RA, some researchers had revealed some correlations of thyroid disorders with other autoimmune diseases like SLE, SS and multiple sclerosis (MS) $(28,29)$. One previous research revealed the correlation between SLE and thyroid diseases (28). In 2010 (29), Alessandro and his colleagues found a higher occurrence of overt hypothyroidism and GD in female SLE patients. Recently, Liu et al. (30) observed a higher prevalence of thyroid disease in SLE patients compared to healthy controls via a large cohort study. Likewise, numerous 
studies found high prevalence of thyroid disorders among SS or MS patients (31-34).

In order to examine the association between RA and thyroid dysfunction statistically and quantitatively, we performed a metaanalysis consisting of 15 independent relevant studies, which revealed a strong correlation between RA and elevated risk of thyroid dysfunction. The meta-analysis also demonstrated a rather positive correlation between RA and elevated risk of overt hypothyroidism, which indicated the clinical importance of conducting thyroid function tests in RA patients. Distinct with the results from our case-control research, the meta-analysis showed a positive relationship between RA and $\mathrm{SCH}$, and a possible reason may be the limited sample size of our study.

The exact mechanism underlying the relationship between RA and thyroid disorders is still unclear. As autoimmune diseases, the etiology of RA and AITD are complex, both genetic and environmental factors are involved (35-39). In line with this, autoimmune diseases generally share similar pathological pathways, which implies the possible aggregation phenomenon of autoimmune diseases. Some gene variations were found to exert great effect in the pathogenesis of both RA and AITD. For instance, numerous studies revealed that single nucleotide polymorphisms (SNPs) of HLA-DRB1 (40-46), STAT4 (47-52), and vitamin D receptor (VDR) (53-58) were associated with RA and AITD. Scientists also observed that smoking and vitamin D deficiency had strong association with RA and AITD (5961). Furthermore, some researchers found that similar immune dysregulation appears in both RA and AITD. Our earlier study demonstrated the imbalance between T helper cell 17 (Th17) and regular T cells (Treg) led to AITD (62), and other studies revealed similar pathogenic role of Th17/Treg imbalance in RA $(63,64)$. Therefore, because thyroid dysfunction is mainly resulted from AITD, the increased risk of thyroid dysfunction in RA patients may be explained by those shared factors involved in the pathogeneses of RA and AITD.

Several limitations of this study need to be taken into consideration. First, the sample size of the case-control study was relatively small, which may lead to deficient statistical power in subgroup analysis. Second, we conducted thyroid functional tests at the recruitment time and did not perform an investigation to monitor thyroid function during follow-up. Since there is a possible assumption that the RA duration may increase the disposition toward thyroid dysfunction, the risk of thyroid dysfunction may differ in RA patient with various durations, which need to be elucidated in future studies. Finally, the impact of thyroid dysfunction on RA prognosis or treatment outcomes is still not well-established. The finding from logistic regression analysis in RA patients revealed that disease duration had no

\section{REFERENCES}

1. Li Q, Laumonnier Y, Syrovets T, Simmet T. Yeast two-hybrid screening of proteins interacting with plasmin receptor subunit: C-terminal fragment of annexin A2. Acta Pharmacol Sin. (2011) 32:1411-8. doi: 10.1038/aps.2011.121

2. Sokka T, Abelson B, Pincus T. Mortality in rheumatoid arthritis: 2008 update. Clin Exp Rheumatol. (2008) 26(5 Suppl. 51):S35-61. obvious impact on the risk of thyroid dysfunction, which was not reliable because of the limited number of RA patients. Therefore, future studies recruiting more RA patients are necessary to determine the impact of disease duration on risk of thyroid dysfunction.

As one of the autoimmune and inflammatory disease, glucocorticoid was widely used to alleviate the inflammation and suppress over-active immune responses in RA patients (65-67). In general conditions, the usage of glucocorticoid exerts litter influence on the regulation of thyroid hormone. However, under some circumstances, the utilization of high-dose glucocorticoid leads to a direct suppression of TSH secretion without increasing FT3 and FT4 (68). Leflunomide, as another drug for the treatment of RA, could affect thyroid function (69). The above data suggest that intake of some drugs for RA may also increase risk of thyroid dysfunction. However, current observational studies which aimed to assess the impact of those drugs on thyroid dysfunction among RA patients were relatively small, further studies with larger sample size are warranted.

In summary, our study reveals an increased prevalence of thyroid dysfunction in RA patients, and RA is an important risk factor for thyroid dysfunction. RA patients are at a higher risk of thyroid dysfunction, especially overt hypothyroidism. Hence, this study suggests that thyroid-related examinations including thyroid auto-antibodies and thyroid function tests should better be included when evaluating RA patients, and further articles to elucidate the mechanisms underlying the relationship between RA and thyroid dysfunction are necessary.

\section{ETHICS STATEMENT}

The research project was approved by the Ethics Committee of the Jinshan hospital, the Institutional Review Board of Jinshan Hospital of Fudan University (No. 2015-KY12-457).

\section{AUTHOR CONTRIBUTIONS}

QL wrote the article. JinZ supervised the whole experiments and the writing of the article. BW helped to designed the experiment. KM, JingZ, YY, WY, and JieZ helped to analyses the data.

\section{ACKNOWLEDGMENTS}

This work was supported by the National Natural Science Foundation of China (Grant Nos. 81471004 and 81670722). The authors would like to thank all of the participants in the study. arthritis in Northern Sweden. J Rheumatol. (1997) 24:4 45-51.

4. Gabriel SE, Michaud K. Epidemiological studies in incidence, prevalence, mortality, and comorbidity of the rheumatic diseases. Arthritis Res Ther. (2009) 11:229. doi: 10.1186/ar2669 
5. Choy E. Understanding the dynamics: pathways involved in the pathogenesis of rheumatoid arthritis. Rheumatology (2012) 51(Suppl. 5):v3-11. doi: 10.1093/rheumatology/kes113

6. Kremers HM, Crowson CS, Therneau TM, Roger VL, Gabriel SE. High tenyear risk of cardiovascular disease in newly diagnosed rheumatoid arthritis patients: a population-based cohort study. Arthritis Rheum. (2008) 58:226874. doi: $10.1002 /$ art.23650

7. Södergren A, Stegmayr B, Lundberg V, Ohman ML, Wållberg-Jonsson S. Increased incidence of and impaired prognosis after acute myocardial infarction among patients with seropositive rheumatoid arthritis. Ann Rheum Dis. (2007) 66:263-6. doi: 10.1136/ard.2006.052456

8. Kirkham BW, Kavanaugh A, Reich K. Interleukin-17A: a unique pathway in immune-mediated diseases: psoriasis, psoriatic arthritis and rheumatoid arthritis. Immunology (2014) 141:133-42. doi: 10.1111/imm.12142

9. Burmester GR, Feist E, Dörner T. Emerging cell and cytokine targets in rheumatoid arthritis. Nat Rev Rheumatol. (2014) 10:77-88. doi: 10.1038/nrrheum.2013.168

10. Devereaux D, Tewelde SZ. Hyperthyroidism and thyrotoxicosis. Emerg Med Clin North Am. (2014) 32:277-92. doi: 10.1016/j.emc.2013.12.001

11. Krassas GE, Poppe K, Glinoer D. Thyroid function and human reproductive health. Endocr Rev. (2010) 31:702-55. doi: 10.1210/er.2009-0041

12. Antonelli A, Macharia BN. Autoimmune thyroid disorders. Autoimmun Rev. (2015) 14:174-80. doi: 10.1016/j.autrev.2014.10.016

13. Cárdenas Roldán J, Amaya-Amaya J, Castellanos-de la Hoz J, Giraldo-Villamil J, Montoya-Ortiz G, Cruz-Tapias P. et al. Autoimmune thyroid disease in rheumatoid arthritis: a global perspective. Arthritis (2012) 2012:864907. doi: 10.1155/2012/864907

14. Przygodzka M, Filipowicz-Sosnowska A. Prevalence of thyroid diseases and antithyroid antibodies in women with rheumatoid arthritis. Pol Arch Med Wewn. (2009) 119:39-43. doi: 10.20452/pamw.600

15. Diaz A, Lipman Diaz EG. Hypothyroidism. Pediatr Rev. (2014) 35:336-47; quiz 348-9. doi: 10.1542/pir.35-8-336

16. Surks MI, Ortiz E, Daniels GH, Sawin CT, Col NF, Cobin RH, et al. Subclinical thyroid disease: scientific review and guidelines for diagnosis and management. JAMA (2004) 291:228-38. doi: 10.1001/jama.291.2.228

17. Arnett FC, Edworthy SM, Bloch DA, McShane DJ, Fries JF, Cooper NS, et al. The American Rheumatism Association 1987 revised criteria for the classification of rheumatoid arthritis. Arthritis Rheum. (1988) 31:315-24. doi: 10.1002/art.1780310302

18. Swartz MK. The PRISMA statement: a guideline for systematic reviews and meta-analyses. J Pediatr Health Care (2011) 25:1-2. doi: 10.1016/j.pedhc.2010.09.006

19. Margulis AV, Pladevall M, Riera-Guardia N, Varas-Lorenzo C, Hazell L, Berkman ND, et al. Quality assessment of observational studies in a drug-safety systematic review, comparison of two tools: the NewcastleOttawa Scale and the RTI item bank. Clin Epidemiol. (2014) 6:359-68. doi: 10.2147/CLEP.S66677

20. Higgins JP, Thompson SG, Deeks JJ, Altman DG. Measuring inconsistency in meta-analyses. BMJ (2003) 327:557-60. doi: 10.1136/bmj.327.7414.557

21. Iddah MA, Macharia BN. Autoimmune thyroid disorders. ISRN Endocrinol. (2013) 2013:509764. doi: 10.1155/2013/509764

22. Lazurova I, Benhatchi K. Autoimmune thyroid diseases and nonorganspecific autoimmunity. Pol Arch Med Wewn. (2012) 122(Suppl. 1):55-9. doi: 10.20452/pamw.1499

23. Hijmans W, Doniach D, Roitt IM, Holborow EJ. Serological overlap between lupus erythematosus, rheumatoid arthritis, and thyroid auto-immune disease. Br Med J. (1961) 2:909-14. doi: 10.1136/bmj.2.5257.909

24. Becker KL, Ferguson RH, Mcconahey WM. The connective-tissue diseases and symptoms associated with Hashimoto's thyroiditis. N Engl J Med. (1963) 268:277-80. doi: 10.1056/NEJM196302072680601

25. Andonopoulos AP, Siambi V, Makri M, Christofidou M, Markou C, Vagenakis AG. Thyroid function and immune profile in rheumatoid arthritis. A controlled study. Clin Rheumatol. (1996) 15:599-603.

26. Acay A, Ulu MS, Ahsen A, Eroglu S, Ozuguz U, Yuksel S, et al. Assessment of thyroid disorders and autoimmunity in patients with rheumatic diseases. Endocr Metab Immune Disord Drug Targets (2014) 14:182-6. doi: $10.2174 / 1871530314666140626113111$
27. Joshi P, Agarwal A, Vyas S, Kumar R. Prevalence of hypothyroidism in rheumatoid arthritis and its correlation with disease activity. Trop Doct. (2017) 47:6-10. doi: 10.1177/0049475515627235

28. Chan AT, Al-Saffar Z, Bucknall RC. Thyroid disease in systemic lupus erythematosus and rheumatoid arthritis. Rheumatology (2001) 40:353-4. doi: 10.1093/rheumatology/40.3.353

29. Antonelli A, Fallahi P, Mosca M, Ferrari SM, Ruffilli I, Corti A, et al. Prevalence of thyroid dysfunctions in systemic lupus erythematosus. Metabolism (2010) 59:896-900. doi: 10.1097/RHU.0b013e31819dbe4c

30. Liu YC, Lin WY, Tsai MC, Fu LS. Systemic lupus erythematosus and thyroid disease-Experience in a single medical center in Taiwan. J Microbiol Immunol Infect. (2017) doi: 10.1016/j.jmii.2016.11.008

31. Fallahi P, Ruffilli I, Giuggioli D, Colaci M, Ferrari SM, Antonelli A, et al. Associations between systemic sclerosis and thyroid diseases. Front Endocrinol. (2017) 8:266. doi: 10.3389/fendo.2017.00266

32. Biró E, Szekanecz Z, Czirják L, Dankó K, Kiss E, Szabó NA, et al. Association of systemic and thyroid autoimmune diseases. Clin Rheumatol. (2006) 25:240-5. doi: 10.1007/s10067-005-1165-y

33. Sloka JS, Phillips PW, Stefanelli M, Joyce C. Co-occurrence of autoimmune thyroid disease in a multiple sclerosis cohort. J Autoimmune Dis. (2005) 2:9. doi: 10.1186/1740-2557-2-9

34. Toki S, Motegi S, Yamada K, Uchiyama A, Ishikawa O. Demographic and clinical features of autoimmune thyroid disorder in Japanese patients with systemic sclerosis. J Dermatol. (2014) 41:1053-7. doi: $10.1111 / 1346-8138.12698$

35. Davies TF, Latif R, Yin X. New genetic insights from autoimmune thyroid disease. J Thyroid Res. (2012) 2012:623852. doi: 10.1155/2012/623852

36. Effraimidis G, Wiersinga WM. Mechanisms in endocrinology: autoimmune thyroid disease: old and new players. Eur J Endocrinol. (2014) 170:R241-52. doi: 10.1530/EJE-14-0047

37. Lee HJ, Li CW, Hammerstad SS, Stefan M, Tomer Y. Immunogenetics of autoimmune thyroid diseases: a comprehensive review. J Autoimmun. (2015) 64:82-90. doi: 10.1016/j.jaut.2015.07.009

38. McLachlan SM, Rapoport B. Breaking tolerance to thyroid antigens: changing concepts in thyroid autoimmunity. Endocr Rev. (2014) 35:59-105. doi: 10.1210/er.2013-1055

39. Miranda DM, Massom JN, Catarino RM, Santos RT, Toyoda SS, Marone $\mathrm{MM}$, et al. Impact of nutritional iodine optimization on rates of thyroid hypoechogenicity and autoimmune thyroiditis: a cross-sectional, comparative study. Thyroid (2015) 25:118-24. doi: 10.1089/thy.2014.0182

40. Diaz-Gallo LM, Ramsköld D, Shchetynsky K, Folkersen L, Chemin K, Brynedal B, et al. Systematic approach demonstrates enrichment of multiple interactions between non-HLA risk variants and HLA-DRB1 risk alleles in rheumatoid arthritis. Ann Rheum Dis. (2018) 77:1454-62. doi: 10.1136/annrheumdis-2018-213412

41. Ting YT, Petersen J, Ramarathinam SH, Scally SW, Loh KL, Thomas R, et al. The interplay between citrullination and HLA-DRB1 polymorphism in shaping peptide binding hierarchies in rheumatoid arthritis. J Biol Chem. (2018) 293:3236-51. doi: 10.1074/jbc.RA117.001013

42. Citera G, Pra FD, Waimann CA, Ficco HM, Alvarellos T, Mas LA, et al. Frequency of human leukocyte antigens class II-DR alleles (HLADRB1) in Argentinian patients with early arthritis. Clin Rheumatol. (2018). doi: 10.1007/s10067-018-4319-4

43. Das S, Baruah C, Saikia AK, Bose S. Associative role of HLA-DRB1 SNP genotypes as risk factors for susceptibility and severity of rheumatoid arthritis: a North-east Indian population-based study. Int J Immunogenet. (2018) 45:17. doi: $10.1111 /$ iji.12347

44. Ramgopal S, Rathika C, Padma MR, Murali V, Arun K, Kamaludeen MN. et al. Interaction of HLA-DRB1* alleles and CTLA4 $(+49 \mathrm{AG})$ gene polymorphism in autoimmune thyroid disease. Gene (2018) 642:430-8. doi: 10.1016/j.gene.2017.11.057

45. Jang HW, Shin HW, Cho HJ, Kim HK, Lee JI, Kim SW, et al. Identification of HLA-DRB1 alleles associated with Graves' disease in Koreans by sequence-based typing. Immunol Invest. (2011) 40:172-82. doi: 10.3109/08820139.2010.525571

46. Jurecka-Lubieniecka B, Ploski R, Kula D, Krol A, Bednarczuk T, Kolosza $\mathrm{Z}$, et al. Association between age at diagnosis of Graves' disease and 
variants in genes involved in immune response. PLoS ONE (2013) 8:e59349. doi: 10.1371/journal.pone.0059349

47. Xia Y, Song J, Feng J, Tian R, Zeng Y, Xiang Y, et al. [STAT4 rs7574865 polymorphism is associated with the susceptibility of rheumatoid arthritis in Wuling mountain area]. Xi Bao Yu Fen Zi Mian Yi Xue Za Zhi (2018) 34:829-33.

48. Duran-Avelar MJ, Vibanco-Pérez N, Hernández-Pacheco RR, CastroZambrano AD, Ortiz-Martínez L, Zambrano-Zaragoza JF. STAT4 rs7574865 G/T polymorphism is associated with rheumatoid arthritis and disease activity, but not with anti-CCP antibody levels in a Mexican population. Clin Rheumatol. (2016) 35:2909-14. doi: 10.1007/s10067-016-3320-z

49. Beltrán Ramírez O, Mendoza Rincón JF, Barbosa Cobos RE, Alemán Ávila I, Ramírez Bello J. STAT4 confers risk for rheumatoid arthritis and systemic lupus erythematosus in Mexican patients. Immunol Lett. (2016) 175:40-3. doi: 10.1016/j.imlet.2016.05.003

50. Ben Hamad M, Cornelis F, Mbarek H, Chabchoub G, Marzouk S, Bahloul $Z$, et al. Signal transducer and activator of transcription and the risk of rheumatoid arthritis and thyroid autoimmune disorders. Clin Exp Rheumatol. (2011) 29:269-74.

51. El-Lebedy D, Raslan H, Ibrahim A, Ashmawy I, El-Aziz SA, Mohammed AM. Association of STAT4 rs7574865 and PTPN22 rs2476601 polymorphisms with rheumatoid arthritis and non-systemically reacting antibodies in Egyptian patients. Clin Rheumatol. (2017) 36:1981-7. doi: 10.1007/s10067-017-3632-7

52. Yan N, Meng S, Zhou J, Xu J, Muhali FS, Jiang W, et al. Association between STAT4 gene polymorphisms and autoimmune thyroid diseases in a Chinese population. Int J Mol Sci. (2014) 15:12280-93. doi: 10.3390/ijms150712280

53. Abd El Gawad SS, Abdul Samee ER, Metwali AA, Abd El Gawad MS. Vitamin D receptor gene polymorphism and its association with 1,25-dihydroxyvitamin $\mathrm{D}(3)$ in patients with Graves disease in an Egyptian population: a pilot study. Endocr Pract. (2012) 18:132-9. doi: 10.4158/EP11131.OR

54. Meng S, He ST, Jiang WJ, Xiao L, Li DF, Xu J, et al. Genetic susceptibility to autoimmune thyroid diseases in a Chinese Han population: role of vitamin D receptor gene polymorphisms. Ann Endocrinol. (2015) 76:684-9. doi: 10.1016/j.ando.2015.01.003

55. Inoue $\mathrm{N}$, Watanabe $\mathrm{M}$, Ishido $\mathrm{N}$, Katsumata $\mathrm{Y}$, Kagawa $\mathrm{T}$, Hidaka $\mathrm{Y}$, et al. The functional polymorphisms of VDR, GC and CYP2R1 are involved in the pathogenesis of autoimmune thyroid diseases. Clin Exp Immunol. (2014) 178:262-9. doi: 10.1111/cei.12420

56. Di Spigna G, Del Puente A, Covelli B, Abete E, Varriale E, Salzano S, et al. Vitamin D receptor polymorphisms as tool for early screening of severe bone loss in women patients with rheumatoid arthritis. Eur Rev Med Pharmacol Sci. (2016) 20:4664-9.

57. Mosaad YM, Hammad EM, Fawzy Z, Abdal Aal IA, Youssef HM, ElSaid TO, et al. Vitamin D receptor gene polymorphism as possible risk factor in rheumatoid arthritis and rheumatoid related osteoporosis. Hum Immunol. (2014) 75:452-61. doi: 10.1016/j.humimm.2014.02.009

58. Song GG, Bae SC, Lee YH. Vitamin D receptor FokI, BsmI, and TaqI polymorphisms and susceptibility to rheumatoid arthritis: a meta-analysis. $Z$ Rheumatol. (2016) 75:322-9. doi: 10.1007/s00393-015-1581-6

59. Herly $M$, Stengaard-Pedersen $K$, Vestergaard $P$, Østergaard $M$, Junker P, Hetland ML, et al. The D-vitamin metabolite 1,25(OH)2
$\mathrm{D}$ in serum is associated with disease activity and anti-citrullinated protein antibodies in active and treatment naive, early rheumatoid arthritis patients. Scand J Immunol. (2018) 88:e12704. doi: 10.1111/sji. 12704

60. Soubrier M, Lambert C, Combe B, Gaudin P, Thomas T, Sibilia J, et al. A randomized, double-blind, placebo-controlled study assessing the efficacy of high doses of vitamin D on functional disability in patients with rheumatoid arthritis. Clin Exp Rheumatol. (2018) 36:1056-60.

61. Wiersinga WM. Clinical relevance of environmental factors in the pathogenesis of autoimmune thyroid disease. Endocrinol Metab. (2016) 31:213-22. doi: 10.3803/EnM.2016.31.2.213

62. Li C, Yuan J, Zhu YF, Yang XJ, Wang Q, Xu J, et al. Imbalance of Th17/Treg in different subtypes of autoimmune thyroid diseases. Cell Physiol Biochem. (2016) 40:245-52. doi: 10.1159/000452541

63. Leipe J, Grunke M, Dechant C, Reindl C, Kerzendorf U, Schulze-Koops H, et al. Role of Th17 cells in human autoimmune arthritis. Arthritis Rheum. (2010) 62:2876-85. doi: 10.1002/art.27622

64. van den Berg WB, Miossec P. IL-17 as a future therapeutic target for rheumatoid arthritis. Nat Rev Rheumatol. (2009) 5:549-53. doi: $10.1038 /$ nrrheum.2009.179

65. Palmowski Y, Buttgereit T, Dejaco C, Bijlsma JW, Matteson EL, Voshaar M, et al. "Official View" on glucocorticoids in rheumatoid arthritis: a systematic review of international guidelines and consensus statements. Arthritis Care Res. (2017) 69:1134-1141. doi: 10.1002/acr.23185

66. Pincus T, Sokka T, Cutolo M. The past versus the present, 1980-2004: reduction of mean initial low-dose, long-term glucocorticoid therapy in rheumatoid arthritis from 10.3 to $3.6 \mathrm{mg} /$ day, concomitant with early methotrexate, with long-term effectiveness and safety of less than 5 mg/day. Neuroimmunomodulation (2015) 22:89-103. doi: 10.1159/0003 62735

67. Robinson DE, Dennison EM, Cooper C, van Staa TP, Dixon WG. A review of the methods used to define glucocorticoid exposure and risk attribution when investigating the risk of fracture in a rheumatoid arthritis population. Bone (2016) 90:107-15. doi: 10.1016/j.bone.2016.06.001

68. Re RN, Kourides IA, Ridgway EC, Weintraub BD, Maloof F. The effect of glucocorticoid administration on human pituitary secretion of thyrotropin and prolactin. J Clin Endocrinol Metab. (1976) 43:338-46.

69. Grzywa M, Kadziela M. [The conversion of hypothyroidism into hyperthyroidism during leflunomide with povidone iodine treatment of rheumatoid arthritis]. Pol Merkur Lekarski (2013) 34:348-50.

Conflict of Interest Statement: The authors declare that the research was conducted in the absence of any commercial or financial relationships that could be construed as a potential conflict of interest.

Copyright (c) $2019 \mathrm{Li}$, Wang, Mu, Zhang, Yang, Yao, Zhu and Zhang. This is an open-access article distributed under the terms of the Creative Commons Attribution License (CC BY). The use, distribution or reproduction in other forums is permitted, provided the original author(s) and the copyright owner(s) are credited and that the original publication in this journal is cited, in accordance with accepted academic practice. No use, distribution or reproduction is permitted which does not comply with these terms. 